УДК 665.658.6

\title{
Genesis Investigation of Ni- and Mo-Based Dispersed Catalysts of Steam Cracking of Heavy Oil
}

\author{
Gleb A. Sosnin ${ }^{* a, b}$, \\ Yurii V. Larichev ${ }^{\mathrm{a}, \mathrm{b}}$, Peter M. Eletskii ${ }^{\mathrm{a}}$, \\ Olesya O. Zaikina ${ }^{a}$, Roman G. Kukushkin ${ }^{a}$, \\ Evgenii Yu. Gerasimov and Vadim A. Yakovlev ${ }^{\mathrm{a}}$ \\ ${ }^{a}$ Boreskov Institute of Catalysis $S B R A S$ \\ 5 Lavrentieva, , Novosibirsk, 630090, Russia \\ ${ }^{b}$ Novosibirsk State University \\ 2 Pirogova Str., Novosibirsk, 630090, Russia
}

This article presents the results of the genesis investigation of $\mathrm{Ni}$ - and Mo-based dispersed steam cracking catalyst produced via in-situ heavy oil emulsion decomposition. The structural characteristics of catalysts and their precursors have been studied by SAXS and TEM for the first time at all stages of production and operation: in reverse emulsions, dispersions and in the coke residues obtained after catalytic steam cracking process It is shown that the Ni-based precursor is converted to larger aggregates during transition from a dispersion in heavy oil to $\mathrm{Ni}_{9} \mathrm{~S}_{8} 10-40 \mathrm{~nm}$ particles in the coke residue. In the case of molybdenum this trend was not revealed, after steam cracking process two types of particles are formed: small layered $\mathrm{MoS}_{2}$ particles with a length of 10-15 $\mathrm{nm}$ and larger $\mathrm{MoO}_{2} 20-30$ nm particles.

Keyword: heavy oil, reversed emulsion, dispersed catalyst, catalytic steam cracking, small angle X-ray scattering, molybdenum, nickel.

DOI: $10.17516 / 1998-2836-0043$.

(C) Siberian Federal University. All rights reserved

* Corresponding author E-mail address: sosningleb@catalysis.ru 


\title{
Исследование генезиса Ni- и Мо-содержащих \\ суспендированных катализаторов \\ парового крекинга тяжелой нефти
}

\author{
Г.А. Соснин ${ }^{\mathrm{a}, \tilde{\sigma}}$, Ю.В. Ларичев ${ }^{\mathrm{a}, \tilde{\sigma}}$, \\ П.М. Елецкий ${ }^{\mathrm{a}}$, О.О. Заикина ${ }^{\mathrm{a}}$, \\ Р.Г. Кукушкин ${ }^{\text {a }}$ Е.Ю. Герасимов ${ }^{\text {a }}$ В.А. Яковлев ${ }^{\mathrm{a}}$ \\ ${ }^{a}$ Институт катализа им. Г.К. Борескова СО РАН \\ Россия, 630090, Новосибирск, пр. Академика Лаврентьева, 5 \\ ${ }^{6}$ Новосибирский государственный университет \\ Россия, 630090, Новосибирск, ул. Пирогова, 2
}

В данной статье приведены результаты исследования генезиса Ni- и Мо-содержащего дисперсного катализатора парового крекинга, полученного эмульсионным методом in-situ в тяжелой нефти методами МУРР и ПЭМ. Впервые исследованы структурные характеристики катализаторов и его предшественников на всех этапах получения и применения: в обратной эмульсии, дисперсии и в коксовом остатке, полученном в ходе каталитического парового крекинга. Показано, что Ni-содержащий предшественник преобразуется в более крупные агрегаты при переходе от дисперсии в тяжелой нефти до частии $\mathrm{Ni}_{9} \mathrm{~S}_{8}$ с размерами частии 10-40 нм в коксовом остатке. В случае молибдена данной зависимости выявлено не было, после проведения проиесса парового крекинга образуется два типа частии: мелкие слоистые частиџы сульфида молибдена с протяженностью 10-15 нм и более крупные частицы оксида молибдена с размерами 20-30 нм.

Ключевые слова: тяжелое нефтяное сырье, тяжелая нефть, обратная эмульсия, дисперсный катализатор, паровой крекинг, малоугловое рентгеновское рассеяние, молибден, никель.

\section{Введение}

В настоящее время легкие и средние нефти являются основными источниками энергии, которые удовлетворяют глобальный спрос на энергоносители из-за их высокого качества, а также низких производственных затрат. Тем не менее в последнее время наблюдается истощение запасов легкой нефти, что вынуждает привлекать к разработке и добыче более тяжелые нефти и битумы [1]. Поэтому в будущем ожидается увеличение их доли в нефтепереработке при соответствующем снижении доли легких нефтей. Однако переработка тяжелых нефтей и битумов затруднена вследствие высокого содержания высокомолекулярных компонентов, включая асфальтены и смолистые соединения, металлов (ванадий, никель, железо и т. д.), серы, азота, кислорода, а также вследствие высокой вязкости, создающей трудности при транспортировке тяжелых нефтей. Но возрастающая потребность в потреблении жидких топлив приводит к поиску новых и совершенствованию существующих технологий переработки тяжелого нефтяного сырья (ТНС). 
Для переработки ТНС в настоящее время используются процессы, основанные на снижении содержания углерода в сырье (термический крекинг, коксование и др.) и на насыщении его водородом (гидрогенизационные процессы), либо различные сочетания данных процессов в зависимости от сырья и рыночной конъюнктуры [2]. Однако переработка ТНС с использованием процессов первого типа приводит к неудовлетворительным выходам ценных светлых фракций углеводородов и характеризуется высоким выходом побочных продуктов (коксовые остатки и газообразные продукты). Применение водорода для облагораживания THC дорогостояще и затруднительно при предобработке такого сырья на местах добычи для дальнейшей транспортировки. Поэтому создание новых технологий переработки ТНС актуальная задача на текущий момент. Одной из таких перспективных технологий является каталитический паровой крекинг - термокаталитический процесс облагораживания ТНС присутствии воды [3-7]. Используемые в процессе парового крекинга катализаторы можно в условно разделить на традиционные - гранулированные (нанесенные и массивные) [8-14] - и суспендированные, добавляемые непосредственно в сырье [15]. По сравнению с нанесенными катализаторами частицы высокодисперсного катализатора, суспендированные в сырье, менее подвержены дезактивации в ходе процессов переработки тяжелого нефтяного сырья. Также к преимуществам суспендированных катализаторов по сравнению с традиционными катализаторами переработки тяжелого сырья можно отнести отсутствие проблем с блокировкой пор, увеличение доступности высокодисперсных активных центров для крупных молекул реагентов - минимизацию диффузионного контроля в ходе реакции [16]. Концентрирование частиц катализатора в коксовом остатке после проведения процесса позволяет извлечь активный компонент из кокса и многократно его использовать в дальнейшем. Для получения частиц катализатора в тяжелых нефтях теоретически применимо большинство методов получения наночастиц: химическое осаждение из паровой фазы, химическое осаждение в растворах, термическое распыление, фото- и радиационное химическое восстановление, высокотемпературное разложение твердых предшественников, золь-гель-синтез и т.д. [17].

Однако большинство вышеуказанных методов применимы только для синтеза небольших количеств наноматериалов в лабораторных условиях. При использовании наноразмерных катализаторов в промышленных масштабах исследователи сталкиваются с проблемами, которые заключаются в оптимизации синтеза и стабилизации синтезированных частиц, а также в разработке метода введения катализатора (или его предшественника) в конкретные реакционные среды. Синтезированные катализаторы должны отвечать следующим требованиям: простое диспергирование в нефтяной среде, химическая совместимость с углеводородной фазой, каталитическая активность и термическая стабильность. Большинство этих проблем успешно решаются с использованием принципа in-situ образования дисперсных частиц катализатора в углеводородной реакционной среде. Одним из способов синтеза является эмульсионный или микроэмульсионный подход для введения предшественников катализатора в углеводородное сырье. Данный метод основан на получении обратных эмульсий, представляющих собой водный раствор прекурсора - нефтяное сырьё в присутствии поверхностно-активных веществ. Стоит отметить, что благодаря амфифильным свойствам асфальтенов и смол, содержащихся в сырье, возможно образование 
стабильных водонефтяных эмульсий без использования синтетических ПАВов $[18,19]$. Асфальтены образуют пленку на границе раздела вода-нефть, выступая в роли стабилизатора раствора прекурсора. Частицы катализатора формируются путем термического или химического осаждения прекурсора из полученной ранее эмульсии. Ключевым элементом данного подхода выступает стабилизация полученных коллоидных частиц синтетическими ПАВами и/или асфальтенами в нефтяной смеси. Для исследования эффективности получившихся наночастиц катализатора, суспендированных непосредственно в тяжелой нефти, необходимо отслеживать их размеры на всех стадиях обработки. Поскольку стандартные методы определения размеров частиц, такие как ПЭМ и РФА, малоэффективны для изучения нефтяных дисперсных систем, в данной работе используется метод малоуглового рентгеновского рассеяния (МУРР), позволяющий изучать как жидкие, так и твердые дисперсные системы и хорошо зарекомендовавший себя при исследовании асфальтенов и их агрегации непосредственно в нефтях или органических растворителях [20-26]. В данной работе с использованием метода МУРР впервые было изучено изменение размеров частиц прекурсора и катализатора на всех стадиях приготовления и после проведения реакции каталитического парового крекинга тяжелой нефти.

\section{Экспериментальная часть}

Методика приготовления дисперсий катализатора в тяжелой нефти

Приготовление обратных эмульсий осуществляли путем диспергирования водных растворов прекурсоров катализатора в тяжелой нефти в присутствии ПАВ при атмосферном давлении и комнатной температуре с использованием диспергатора T 25 basic ULTRA-TURRAX фирмы IKА (Германия).

Стадии приготовления:

1. Получение водного раствора прекурсора путем растворения заданного количества соответствующей соли в воде. В опытах были использованы растворы прекурсоров с определенной концентрацией для достижения содержания металла в конечной эмульсии 20000 ppm.

2. Приготовление раствора ПАВ в углеводородном сырье. Для приготовления эмульсий использовали тяжелую нефть (ТН), с которой смешивали необходимое количество ПАВ Span80 с помощью диспергатора (при 24000 об/мин в течение 3 мин.) для достижения в конечной эмульсии содержания ПАВ 5 мас. \%.

3. Приготовление обратной эмульсии предшественника. К полученному раствору ПАВа в нефтяном сырье добавляли необходимое количество водного раствора прекурсора (нитрат никеля, парамолибдат аммония - ПМА) и смешивали с помощью диспергатора при вышеуказанных параметрах.

Каталитические дисперсии (суспензии) прекурсоров катализатора в сырье получали путем термообработки обратных эмульсий в инертной атмосфере аргона. Температурные условия $\left(210^{\circ} \mathrm{C}\right)$ подбирали с учетом свойств исходной тяжелой нефти $\left(\mathrm{T}_{\text {н.к. }}=225^{\circ} \mathrm{C}\right)$ во избежание выкипания светлых углеводородных фракций, а также для обеспечения частичного разложения предшественника катализатора. Полученные эмульсии подвергали термообработке в муфельной печи при $210{ }^{\circ} \mathrm{C}$ в течение 1 ч. Время нагрева до нужной температуры составляло 30 мин. 
Методика выделения асфальтенов и металлсодержащих частиц

Асфальтеновые агрегаты, содержащие прекурсор катализатора, выделяли по стандартной методике осаждения асфальтенов в 40-кратном избытке н-гексана [27]. Асфальтены отделяли от полученного раствора нефти на фарфоровом фильтре с использованием колбы Бунзена под вакуумом. Осадок отмывали н-гексаном до получения прозрачного раствора.

\section{Методика проведения каталитического парового крекинга}

В дисперсию частиц катализатора в ТН добавляли воду, далее реактор герметизировали и опрессовывали установку аргоном при давлении 10 МПа. Затем проводили дополнительную продувку аргоном для вытеснения остатков воздуха. Эксперименты по каталитическому паровому крекингу тяжелой нефти осуществляли при постоянном перемешивании со скоростью 1000 об/мин при $425^{\circ} \mathrm{C}$ в течение 1 ч. Скорость нагрева до необходимой температуры составляла $5{ }^{\circ} \mathrm{C} /$ мин. После проведения каталитического парового крекинга смесь продуктов разделяли по методике, представленной в [28].

\section{Малоугловое рентгеновское рассеяние (МУРР)}

Для получения данных малоуглового рентгеновского рассеяния (МУРР) использовали дифрактометр S3 MICRO («HECUS») с точечной коллимацией и медным излучением $\left(\mathrm{CuK}_{\alpha}\right.$, 50 Вт). Измерения рентгенограмм проводили в интервале векторов q от 0,01 до $0,60 \AA^{-1}$, где $\mathrm{q}=4 \pi \sin \theta / \lambda$. Образцы исследовали в кварцевом капилляре с внутренним диаметром 1,5 мм. При исследовании жидких образцов из полученных малоугловых кривых вычитались фоновые малоугловые кривые от соответствующих образцов с учетом коэффициентов поглощения. В качестве образцов сравнения использовали деасфальтизованную нефть и подготовленные образцы без соединений никеля. Для определения радиуса инерции частиц $\left(\mathrm{R}_{\mathrm{G}}\right)$ определяли тангенс угла наклона кривой МУРP в координатах $\left(\ln \left(\mathrm{I}(\mathrm{q}) ; \mathrm{q}^{2}\right)[29]\right.$. Обработку экспериментальных данных осуществляли с помощью программного обеспечения ATSAS [30] и SasView (http:// www.sasview.org).

Для селективного выделения малоуглового рассеяния от металлсодержащих (Ni и $\mathrm{Mo}$ ) частиц в коксах и асфальтенах была использована ранее разработанная методика полного контраста на основе фторуглеродных соединений $[31,32]$. Для этого образец в капилляре заполняют специальной жидкостью с плотностью, приблизительно соответствующей плотности углеродной матрицы. Применение такого контраста позволяет селективно погасить рассеяние от углеродной матрицы и получить остаточный сигнал малоуглового рассеяния только от металлсодержащих частиц, поскольку они имеют существенно большую плотность и не могут быть законтрастированы используемой жидкостью. Более детально методика изложена в работе [31, 32].

\section{Просвечивающая электронная микроскопия высокого разрешения (ПЭМВР)}

Исследование образцов методом электронной микроскопии высокого разрешения проводили с использованием просвечивающего электронного микроскопа JEM-2010 фирмы JEOL (Япония) с ускоряющим напряжением 200 кВ и разрешением 0,14 нм. Частицы образца нано-

$$
-493-
$$


сили путем диспергирования его взвеси в спирте на алюминиевую подложку с применением ультразвукового диспергатора.

\section{Результаты и обсуждение}

Эмульсионный метод получения дисперсных частиц катализатора в тяжелом нефтяном сырье подразумевает разрушение водонефтяной эмульсии прекурсора с образованием дисперсии частиц катализатора, далее используемой в процессе парового крекинга тяжелой нефти. После проведения процесса данные частицы концентрируются в коксовых отложениях. Таким образом, изучаемые системы на разных этапах формирования частиц катализатора можно разделить на следующие:

1. Эмульсия предшественника катализатора тяжелой нефти.

2. Дисперсия частично разложившегося прекурсора катализатора в виде взвеси твердых наночастиц в тяжелой нефти. Дополнительно были исследованы асфальтеновые агрегаты, содержащие частицы катализатора, выделенные из дисперсии методом деасфальтизации.

3. Коксовые отложения после проведения каталитического парового крекинга, содержащие наночастицы сформировавшегося дисперсного катализатора.

В качестве поверхностно-активного вещества для стабилизации водонефтяных эмульсий использовали неионогенный маслорастворимый $\mathrm{Span} 80$ - сложный эфир спирта сорбитана и олеиновой кислоты. При введении данного ПАВа образование упорядоченных структур не наблюдается, однако было обнаружено, что сама добавка обладает дезагрегирующими свойствами, уменьшая размер асфальтеновых агрегатов (рис. 1a). Введение воды, по-видимому, слабо сказывается на размере асфальтеновых агрегатов, поскольку большая часть добавленной воды присутствует в виде крупных капель (>100 нм), которые из-за больших размеров невозможно охарактеризовать методом МУРР.
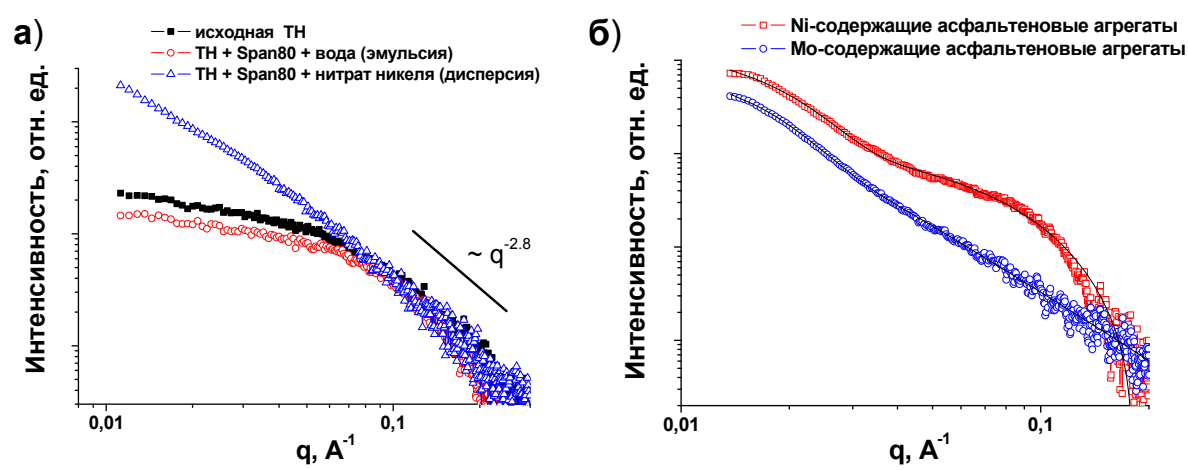

Рис. 1 Кривые МУРР для образца исходной нефти и дисперсий с добавками ПАВа (Span80) и нитрата никеля (а); Кривые МУРР для Ni- и Мо-содержащих агрегатов присутствующих в выделенных из соответствующих дисперсий асфальтенов (б). Сплошной линией приведено описание данных с использованием модели Г. Боукейдж [35]

Fig. 1 SAXS curves for a sample of heavy oil and dispersions with surfactant additives (Span80) and nickel nitrate (a); SAXS curves for Ni and Mo-containing aggregates present in asphaltenes isolated from the corresponding dispersions (b). The solid line gives a description of the data using the model of G. Beaucage [35] 
Таблица 1. Величины радиусов инерции $\left(\mathrm{R}_{\mathrm{G}}\right)$ для $\mathrm{Ni}-$ и Мо-содержащих образцов

Table 1. The values of the radii of inertia $\left(\mathrm{R}_{\mathrm{G}}\right)$ for Ni- and Mo-containing samples

\begin{tabular}{|l|l|l|l|}
\hline \multicolumn{1}{|c|}{ Ni-содержащие образцы } & \multicolumn{1}{|c|}{$\mathrm{R}_{\mathrm{G}}, \mathrm{HM}$} & \multicolumn{1}{c|}{ Мо-содержащие образцы } & \multicolumn{1}{c|}{$\mathrm{R}_{\mathrm{G}}, \mathrm{HM}$} \\
\hline Исходная $\mathrm{TH}$ & $2,9 \pm 0,3$ & Исходная $\mathrm{TH}$ & $2,9 \pm 0,3$ \\
\hline Эмульсия: $\mathrm{TH}+\mathrm{Span} 80+\mathrm{H}_{2} \mathrm{O}$ & $2,7 \pm 0,3$ & Эмульсия: $\mathrm{TH}+\mathrm{Span} 80+\mathrm{H}_{2} \mathrm{O}$ & $2,7 \pm 0,3$ \\
\hline Дисперсия: $\mathrm{TH}+\mathrm{Span} 80+\mathrm{Ni}\left(\mathrm{NO}_{3}\right)_{2}$ & $15,2 \pm 0,4$ & Дисперсия: TH+Span80+ПМА & $11,0 \pm 0,4$ \\
\hline Ni-содержащие асфальтеновые агрегаты & $10,2 \pm 0,4$ & $\begin{array}{l}\text { Мо-содержащие асфальтеновые } \\
\text { агрегаты }\end{array}$ & $10,9 \pm 0,4$ \\
\hline Ni-содержащие частицы в коксе & $11,5 \pm 0,4$ & Мо-содержащие частицы в коксе & $8,2 \pm 0,4$ \\
\hline
\end{tabular}

Добавление нитрата никеля и ПМА в систему с последующим удалением воды приводит к кардинальным изменениям (табл. 1). Можно предположить образование крупных агрегатов, состоящих из молекул Span80, солей металлов, а также асфальтенов и смол. Как видно по данным (рис. 1б), степень спада кривой МУРР в области дальних углов (q > 0,10 $\left.\AA^{-1}\right)$ экстраполируется функцией $\mathrm{I}(\mathrm{q}) \sim \mathrm{q}^{-\mathrm{x}}$, где х равняется 2,8. Этот показатель может соответствовать либо анизометрическим частицам с различной геометрической формой, либо частицам с фрактальным строением [33, 34]. Исходя из полученных данных, можно предполагать фрактальное строение агрегатов, состоящих из металлсодержащих ядер и углеводородной оболочки.

Для дальнейшего анализа были исследованы асфальтены, выделенные из полученных нефтяных дисперсий осаждением н-гексаном и содержащие соединения никеля и молибдена. На рис. 16 приведены кривые МУРР, полученные при использовании контраста с подавлением основного фона рассеяния от асфальтенов при контрастировании [31, 32]. Таким образом, наблюдаемое малоугловое рассеяние было обусловлено преимущественно агрегатами Ni-ПАВасфальтены и Мо-ПАВ-асфальтены. Из данных табл. 1 видно, что Ni-содержащие агрегаты после выделения из нефти претерпевают существенное уменьшение размеров, по всей вероятности, происходит некоторая усадка рыхлых агрегатов. В то же время в случае Мо-содержащих агрегатов подобной усадки не наблюдается. Также для описания этих кривых МУРР было использовано универсальное экспоненциально-степенное приближение [35], применяемое для описания многоуровневых фрактальных объектов. Кривая МУРР для Ni-содержащих асфальтеновых агрегатов описывается двухуровневой организацией частиц в матрице: I уровень компактных первичных частиц и II уровень рыхлых вторичных агрегатов из первичных частиц. Величина радиуса инерции частиц первого уровня составила 1,8 нм, а для частиц второго уровня - 10,4 нм, что практически совпадает с ранее определенной величиной радиуса инерции в приближении Гинье для данного образца (табл. 1). Таким образом, компактные $\mathrm{Ni}$-содержащие частицы с величиной радиуса инерции 1,8 нм (в приближении сплошных сфер данная величина радиуса инерции соответствует диаметру сфер, равному 4,6 нм) образуют рыхлый вторичный агрегат, обладающий уже величиной радиуса инерции 10,4 нм и структурно близкий к модели массового фрактала. В случае Мо-содержащих асфальтеновых агрегатов подобной иерархичности выявить не удалось, для описания полученных данных оказалось достаточно одноуровневой модели Боукейдж [35]. Можно предполагать, что в этом случае Мо-содержащие частицы равномерно распределены в углеродной матрице и не обладают каким-либо дополни- 
тельным упорядочением. Также следует отметить, что в случае Мо-содержащих комплексов доля асфальтенов, смол и ПАВ достаточно высокая, поскольку полученные величины радиусов инерции для Ni- и Мо-содержащих частиц в асфальтенах практически идентичны. То есть в отличие от комплекса, состоящего из первичных $\mathrm{Ni}$-содержащих частиц, Мо-содержащий комплекс, имеющий более равномерное распределение в углеводородной среде, преимущественно состоит из углеродсодержащей оболочки (асфальтены, смолы, ПАВ), которая стабилизирует молибденсодержащие частицы.

Полученные металлсодержащие нефтяные дисперсии были исследованы в процессе каталитического парового крекинга тяжелой нефти в статическом режиме. Было обнаружено, что использование $\mathrm{Ni-coдержащих} \mathrm{частиц} \mathrm{в} \mathrm{процессе} \mathrm{парового} \mathrm{крекинга} \mathrm{приводит} \mathrm{к}$ увеличению соотношения $\mathrm{H}: \mathrm{C}$ и снижению содержания серы в жидких продуктах, однако наблюдается повышение выхода кокса со снижением выхода жидких продуктов по сравнению с паровым крекингом без использования катализатора. В случае Мо-содержащих частиц, напротив, не наблюдается увеличение выхода кокса. Данное различие в поведении Ni- и Мо-содержащих частиц, помимо различной химической природы, может быть связано с различной толщиной оболочки стабилизирующих асфальтеновых агрегатов, поскольку с увеличением плотности последней вероятность коксообразования увеличивается за счет роста концентрации свободных радикалов вблизи металлсодержащих частиц в ходе термохимических процессов.

Металлсодержащие частицы, концентрирующиеся в коксе после проведения процесса парового крекинга, были исследованы методами ПЭМ и МУРР. Для анализа Ni- и Мо-содержащих частиц в коксах методом МУРР также применялось контрастирование [31, 32] для существенно-

Таблица 2. Выходы продуктов термического крекинга ТН, парового крекинга без катализатора и каталитического парового крекинга (температура $425^{\circ} \mathrm{C}$, продолжительность 1 ч)

Table 2. Parameters of thermal cracking products, steam cracking without catalyst and catalytic steam cracking $\left(425^{\circ} \mathrm{C}, 1\right.$ hour)

\begin{tabular}{|c|c|c|c|c|c|}
\hline \multirow{3}{*}{ Показатель } & \multirow{3}{*}{$\mathrm{TH}^{1}$} & \multicolumn{4}{|c|}{ Выход, мас. \% } \\
\hline & & \multirow{2}{*}{$\mathrm{TK}^{2}$} & \multirow{2}{*}{$\Pi \kappa^{3}$} & \multicolumn{2}{|c|}{ КПК ${ }^{4}$} \\
\hline & & & & $2 \% \mathrm{Ni}$ & $2 \% \mathrm{Mo}$ \\
\hline $\begin{array}{l}\text { Светлые фракции } \\
\left(\mathrm{T}_{\text {кип }}<350^{\circ} \mathrm{C}\right)\end{array}$ & 21 & 47 & 50 & 46 & 51 \\
\hline Синтетическая нефть (фракции с $\left.\mathrm{T}_{\text {кип }}<500{ }^{\circ} \mathrm{C}\right)$ & 52 & 65 & 64 & 59 & 66 \\
\hline $\begin{array}{l}\text { Полусинтетическая нефть (жидкие продукты } \\
\text { суммарно) }\end{array}$ & 100 & 83 & 82 & 76 & 82 \\
\hline Кокс & - & 8 & 7 & 13 & 8 \\
\hline Газ & - & 2 & 2 & 4 & 3 \\
\hline Баланс & 100 & 93 & 91 & 93 & 93 \\
\hline Содержание S в жидких продуктах, мас. \% & 4,3 & 3,5 & 3,3 & 2,9 & 2,8 \\
\hline $\begin{array}{l}\text { Соотношение Н : С } \\
\text { в жидких продуктах }\end{array}$ & 1,74 & 1,61 & 1,64 & 1,69 & 1,70 \\
\hline
\end{tabular}

${ }^{1}$ Исходная тяжелая нефть. ${ }^{2}$ Термический крекинг. ${ }^{3}$ Паровой крекинг без катализатора. ${ }^{4}$ Каталитический паровой крекинг. ${ }^{5}$ Выход кокса с учетом зольности. 
a)

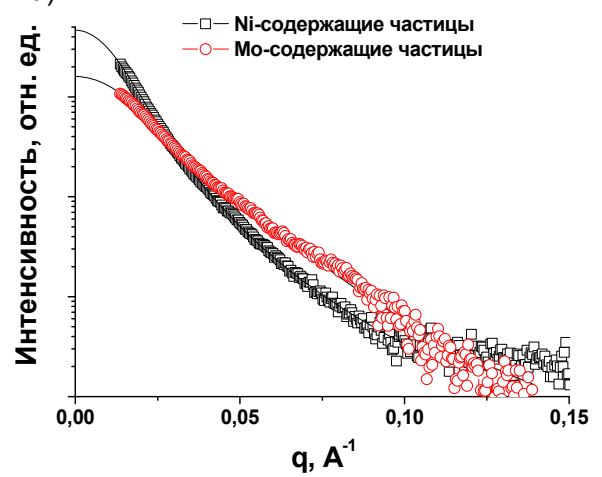

б)

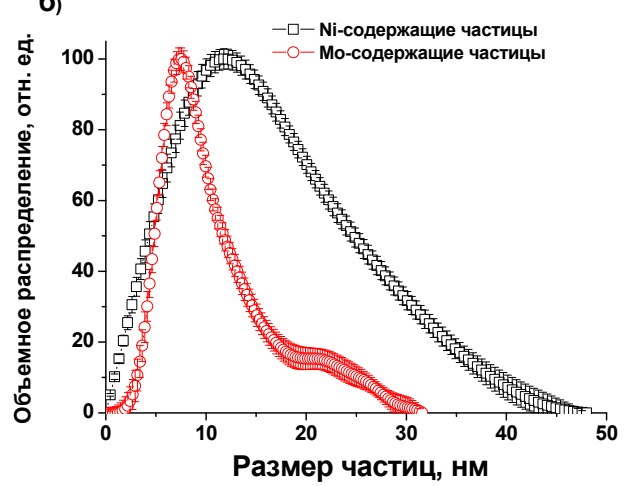

Рис. 2. Кривые МУРР для Ni- и Мо-содержащих частиц в коксовых остатках (а); объемные распределения частиц по размерам для $\mathrm{Ni}$ - и Мо-содержащих частиц в коксовых остатках (б)

Fig. 2. SAXS curves for Ni- and Mo-containing particles in coke residues (a); size distributions for Ni- and Mocontaining particles in coke residues (б)

го уменьшения паразитного рассеяния от углеродной матрицы. Полученные данные малоуглового рассеяния относятся к частицам, обладающим существенно большей плотностью относительно углерода. Из приведенных кривых МУРР были расчитаны распределения частиц по размерам в приближении сферических частиц (рис. 2). Как видно из данных, представленных в рис. 2, табл. 2, Ni-содержащие частицы укрупняются, тогда как Мо-содержащие, напротив, уменьшаются в размерах. Причем Ni-содержащие частицы обладают большими размерами и существенно более широким распределением по размерам по сравнению с Мо-содержащими частицами. Однако для Мо-содержащих частиц в полученном распределении можно выделить две моды частиц по размерам. Таким образом, наличие упорядочения $\mathrm{Ni}$-содержащих частиц в асфальтенах приводит к большей агрегации в процессе крекинга при образовании кокса. Тогда как Мо-содержащие частицы, распределенные более равномерно в асфальтеновой матрице, обладают большей стабильностью к агрегации.

Исследование методом ПЭМВР коксового остатка после каталитического парового крекинга в присутствии Ni-содержащего катализатора (рис. $3 a$ ) показало, что образец представляет собой аморфную углеродную матрицу, включающую в себя активный компонент, который находится в виде хорошо окристаллизованной фазы $\mathrm{Ni}_{9} \mathrm{~S}_{8}$ (данная стехиометрия установлена по результатам измерения межплоскостного расстояния частиц и РФА коксовых остатков (более подробная информация представлена в [36]). Частицы сульфида никеля имеют форму параллелепипедов и кубов с размерами в разных направлениях от 10 до 40 нм, что хорошо согласуется с данными МУРР. При исследовании методом ПЭМВР продуктов уплотнения каталитического парового крекинга в присутствии Мо-катализатора (рис. 3б), было установлено, что молибден находится в виде двух фаз в матрице аморфного углерода: частиц $\mathrm{MoO}_{2}$ с размерами 20-30 нм (хотя наблюдались и более крупные частицы) и слоистых частиц $\operatorname{MoS}_{2}$, протяженность которых составляет 10-15 нм (более подробно в [28]). Следует отметить, что $\mathrm{MoS}_{2}$ находится как в непосредственном контакте с частицами оксида молибдена, так и на некотором расстоянии от них. Эти результаты также согласуются с данными МУРР, согласно которым распределение Мо-содержащих частиц содержит две моды: мелкие частицы с размерами 5-15 нм и крупные

$$
-497-
$$



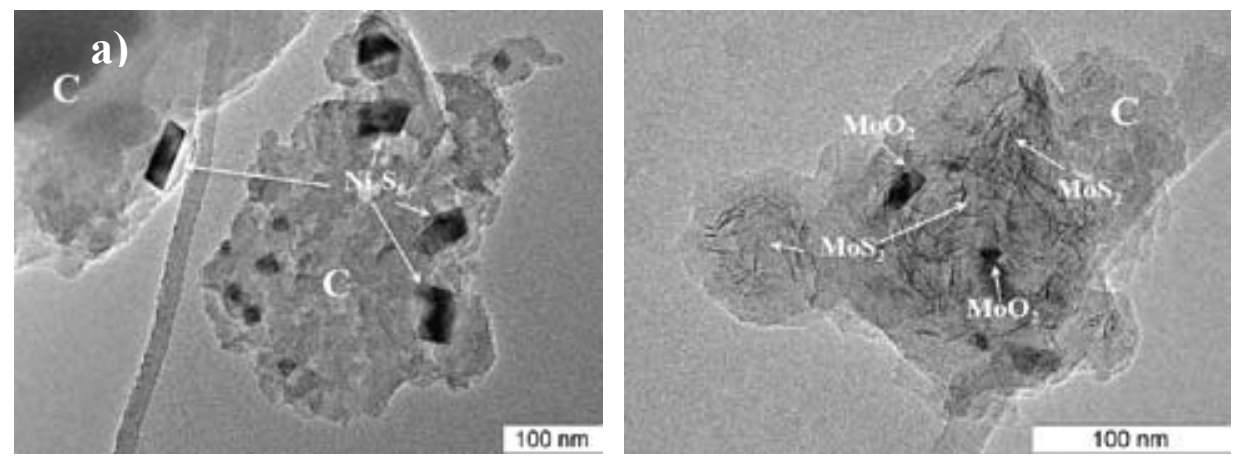

Рис. 3. Типичные ПЭМ-снимки образцов коксового остатка с дисперсным Ni- и Мо-содержащим катализатором после эксперимента по каталитическому паровому крекингу ТН

Fig. 3. Typical TEM images of coke residue samples with a dispersed Ni- and Mo-containing catalyst after the catalytic steam cracking experiment

с размерами от 15 до 30 нм. По-видимому, $\mathrm{MoS}_{2}$ относится к первому типу частиц, а $\mathrm{MoO}_{2}$ ко второму.

\section{Заключение}

Впервые методом МУРР исследованы структурные характеристики дисперсного катализатора парового крекинга на основе никеля и молибдена на различных этапах его приготовления. Установлено, что при введении ПАВа и солей переходных металлов в тяжелую нефть возможно образование различных агрегатов, состоящих из металлсодержащего центра и углеводородной оболочки. В случае $\mathrm{Ni}$-содержащих частиц обнаружено образование рыхлых вторичных агрегатов, состоящих из более мелких первичных частиц. Наблюдаемое иерархичное строение Ni-содержащих агрегатов может быть причиной агрегации никелевых частиц в ходе проведения процесса парового крекинга. В случае Мо-содержащих частиц, напротив, можно отметить высокую стабильность получаемых дисперсий и незначительную агрегацию. Показано, что никельсодержащий предшественник после проведения процесса парового крекинга превращается в сульфид никеля с размерами частиц от 10 до 40 нм, превосходящими исходные размеры частиц предшественника в асфальтеновых агрегатах $\left(\mathrm{R}_{\mathrm{G}}=10,2 \mathrm{Hм}\right)$, что может свидетельствовать об агрегации данных частиц. В случае молибдена подобной тенденции не наблюдается, после проведения процесса парового крекинга образуется два типа частиц: мелкие слоистые частицы сульфида молибдена с протяженностью 10-15 нм и более крупные частицы оксида молибдена с размерами 20-30 нм.

\section{Работа выполнена при финансовой поддержке РНФ (проект №15-13-00106).}

\section{Список литературы}

1. Oil, World Energy Outlook, International Energy Agency, 2014

2. Анчита X., Спейт Д. Переработка тяжелых нефтей и нефтяных остатков. Гидрогенизационные процессы. СПб., ЦОП Профессия, 2012. 384 с. [Ancheyta J. Speight J.G. Hydroprocessing of heavy oils and residua. Boca Raton, London, New York: CRC Press, 2007. 335 p.] 
3. Olvera J.N.R., Gutiérrez G.J., Serrano J.A.R., Ovando A.M., Febles V.G., Arceo L.D.B. Use of unsupported, mechanically alloyed $\mathrm{NiWMoC}$ nanocatalyst to reduce the viscosity of aquathermolysis reaction of heavy oil. Catalysis Communications. 2014. Vol. 43, P. 131-135.

4. Shokrlu, Y.H., Babadagli, T. Viscosity reduction of heavy oil/bitumen using micro- and nanometal particles during aqueous and non-aqueous thermal applications. Journal of Petroleum Science and Engineering. 2014. Vol. 119, P. 210-220.

5. S. Desouky, A. Alsabagh , M. Betiha, A. Badawi, A. Ghanem, and S. Khalil Catalytic aquathermolysis of Egyptian heavy crude oil International Journal of Chemical, Molecular, Nuclear, Materials and Metallurgical Engineering. 2013. Vol. 7(8), P. 286-291.

6. Oki Muraza, Ahmad Galadima Aquathermolysis of heavy oil: a review and perspective on catalyst development. Fuel. 2015. Vol. 157, P.219-231.

7. Dutta R.P., McCaffrey W.C., Gray M.R., Muehlenbachs K Thermal cracking of athabasca bitumen: Influence of steam on reaction chemistry. Energy Fuels. 2000. Vol. 14(3), P.671-676.

8. Sharypov, V.I., Kuznetsov, B.N., Beregovtsova, N.G. Steam cracking of coal-derived liquids and some aromatic compounds in the presence of haematite Fuel. 1996. Vol. 75(7), P. 791794.

9. Hashemi, R., Nassar, N.N., Almao, P.P. Enhanced heavy oil recovery by in situ prepared ultradispersed multimetallic nanoparticles: A study of hot fluid flooding for athabasca bitumen recovery Energy Fuels. 2013. Vol. 27(4), P. 2194-2201.

10. Nassar, N.N., Hassan, A., Almao, P P. Application of nanotechnology for heavy oil upgrading: Catalytic steam gasification/cracking of asphaltenes Energy Fuels. 2011. Vol. 25(4), P. 1566-1570.

11. Fumoto, E., Tago, T., Tsuji, T., Masuda, T. Recovery of useful hydrocarbons from petroleum residual oil by catalytic cracking with steam over zirconia-supporting iron oxide catalyst Energy Fuels. 2004. Vol. 18, P. 1770-1774.

12. Fumoto, E., Tago, T., Masuda, T. Production of lighter fuels by cracking petroleum residual oils with steam over zirconia-supporting iron oxide catalysts Energy Fuels. 2006. Vol. 20(1), P. 1-6.

13. Fumoto, E., Matsumura, A., Sato, S., Takanohashi, T. Recovery of lighter fuels by cracking heavy oil with zirconia-alumina-iron oxide catalysts in a steam atmosphere Energy Fuels. - 2009. Vol. 23, P. 1338-1341.

14. Funai, S., Fumoto, E., Tago, T., Masuda, T. Recovery of useful lighter fuels from petroleum residual oil by oxidative cracking with steam using iron oxide catalyst Chemical Engineering Science. 2010. Vol. 65. P. 60-65.

15. US patent 5688395, J. Carrazza Process and catalyst for upgrading heavy hydrocarbon Publ. Date 18.11.1997

16. Kennepoh D., Sanford E. Conversion of athabasca bitumen with dispersed and supported Mo-based catalysts as a function of dispersed catalyst concentration, Energy Fuel, 1996 Vol. 10(1), P. 229-234

17. Das SK, Choi SU, Yu W, Pradeep T. Nanofluids: science and technology. Wiley-Interscience; 2007.

18. B. Siffert, C. Bourgeois, E. Papirer Structure and water-oil emulsifying properties of asphaltenes Fuel, 1984, Vol. 63, P. 834-837 
19. Khadzhiev S.N., Kadiev K.M., Yampolskaya G.P., Kadieva M.Kh. Trends in the synthesis of metal oxide nanoparticles through reverse microemulsions in hydrocarbon media Advances in Colloid and Interface Science 2013. Vol. 197-198, P. 132-145

20. Barré L.. In X-ray and Neutron Techniques for Nanomaterials Characterization. (Eds. C. S.S.R. Kumar). Springer, Berlin Heidelberg, 2016, p. 665.

21. Gawrys K., Blankenship G., Kilpatrick P.. Solvent entrainment in and flocculation of asphaltenic aggregates probed by small-angle neutron scattering Langmuir 2006. Vol. 22(10), P.44874497

22. Hoepfner M., Vilas Boas Favero C., Haji-Akbari N., Fogler H.S.. The Fractal Aggregation of Asphaltenes Langmuir 2013, Vol. 29(28), P. 8799-8808

23. Yarranton H.W., Ortiz D.P., Barrera D.M., Baydak E.N., Barre L., Frot D., Eyssautier J., Zeng H., Xu Z., Dechaine G., Becerra M., Shaw J.M., McKenna A.M., Mapolelo M.M., Bohne C., Yang Z., Oake J. On the Size Distribution of Self-Associated Asphaltenes Energy Fuels 2013.Vol. 27(9), P. 5083-5106

24. Spiecker P.M., Gawrys K.L., Trail C.B., Kilpatrick P.K. Effects of petroleum resins on asphaltene aggregation and water-in-oil emulsion formation Colloids and Surfaces A: Physicochem. Eng. Aspects 2003. Vol. 220(1-3), P. 9-27

25. Tuzikov F.V., Larichev Y.V., Borisova L.S., Kozhevnikov I.V., Martyanov O.N. Small-Angle Scattering Study of Colloidal Particles in Heavy Crude Oils Petroleum Chemistry. 2011. Vol. 51(4), P. 281-285.

26. Larichev Y.V., Nartova A.V., Martyanov O.N. The Influence of Different Organic Solvents on the Size and Shape of Asphaltene Aggregates Studied via Small-Angle X-Ray Scattering and Scanning Tunneling Microscopy Adsorption Science and Technology. 2016. Vol. 34(2-3), P. 244-257.

27. ASTM (2012) Standard test method for determination of asphaltenes (heptane insolubles) in crude petroleum and petroleum products; D6560, West Conshohocken, PA.

28. Mironenko O.O., Sosnin G.A., Eletskii P.M., Gulyaeva Y.K., Bulavchenko O.A., Stonkus O.A., Rodina V.O., Yakovlev V.A. A Study of the Catalytic Steam Cracking of Heavy Crude Oil in the Presence of a Dispersed Molybdenum-Containing Catalyst Petroleum Chemistry. 2017. Vol. 57(7), P. 618-629.

29. L. Feigin, D. Svergun. Structure analysis by small angle X-ray and neutron scattering. Plenum Press, NewYork, 1987. P.335

30. Konarev, P.V., Petoukhov, M.V., Volkov, V.V., Svergun, D.I. ATSAS 2.1, a program package for small-angle scattering data analysis Journal of Applied Crystallography 2006. Vol. 39(2), P. 277286.

31. Larichev Y.V., Tuzikov F.V. Advances in Small-Angle X-Ray Scattering for the Study of Supported Catalysts Journal of Applied Crystallography. 2013. Vol. 46(3), P. $752-757$.

32. Larichev Y.V., Tuzikov F.V. New Asking Liquids for the Analysis of Supported Catalysts and Functional Materials by Small-Angle X-Ray Scattering Kinetics and Catalysis. 2013. Vol. 54(5), P. 632-637.

33. Bale H.D., Schmidt P.W. Small-Angle X-Ray-Scattering Investigation of Submicroscopic Porosity with Fractal Properties Phys. Rev. Lett. 1984. Vol. 53(4), P. 596-599.

34. Teixeira J. Small-angle scattering by fractal systems Journal of Applied Crystallography 1988. Vol. 21(6). P. 781-785. 
35. Beaucage, G. Small-Angle Scattering from Polymeric Mass Fractals of Arbitrary MassFractal Dimension Journal of Applied Crystallography 1996, Vol. 29(2), P. 134-149.

36. Yeletskii P.M., Mironenko O.O., Sosnin G.A., Bulavchenko O.A., Stonkus O.A., Yakovlev V.A. Investigating the Process of Heavy Crude Oil Steam Cracking in the Presence of Dispersed Catalysts. II: Investigating the Effect of Ni-Containing Catalyst Concentration on the Yield and Properties of Products Catalysis in Industry. 2016. Vol. 8(4), P. 328-335. 